\title{
Comparative study of nitroglycerin dermal patch versus nifedipine in the management of preterm labour
}

\author{
Manjeet Kaur $^{1 *}$, Bharti Goel ${ }^{1}$, Jasveer Singh ${ }^{2}$
}

\begin{abstract}
${ }^{1}$ Department of Obstetrics and Gynecology, ${ }^{2}$ Department of Anaesthesiology, Government Medical College and Hospital, Chandigarh, Punjab, India
\end{abstract}

Received: 05 August 2018

Accepted: 14 September 2018

\author{
*Correspondence: \\ Dr. Manjeet Kaur, \\ E-mail: drmanjeetkaur99@gmail.com
}

Copyright: (c) the author(s), publisher and licensee Medip Academy. This is an open-access article distributed under the terms of the Creative Commons Attribution Non-Commercial License, which permits unrestricted non-commercial use, distribution, and reproduction in any medium, provided the original work is properly cited.

\begin{abstract}
Background: The aim of present study was to compare the effect of nitroglycerin dermal patch and nifedipine for taking control of preterm labor (tocolysis) and to find the safer drug for mother and foetus.

Methods: Women with signs and symptoms of preterm labor between gestational ages 26-37 weeks were studied. These women were divided into 2 groups. Group A-50 women were prescribed nitroglycerin dermal patch and in Group B-50 women were given nifedipine. Primary outcome of the study was to delay the delivery for at least 48 hours. Secondary outcomes were gestational age at the time of delivery, prolongation of labor, effect on neonate and adverse effects.

Results: Both groups were comparable regarding cervical effacement in $\mathrm{cm}$ and gestational age in weeks at the time of enrollment. Gestational age at the time of delivery in weeks $(p<0.01)$, prolongation of pregnancy in days $(p>$ 0.05), neonatal Apgar score at 5 minutes ( $\mathrm{p}<0.05)$, neonatal weight in $\mathrm{kg}(\mathrm{p}<0.05)$ and foetal outcomes were better in nifedipine group in comparison to nitroglycerin. The overall side effects were less in nifedipine group as compared to nitroglycerin group. Overall success rate was $88 \%$ with nifedipine and $76 \%$ in nitroglycerin cases.

Conclusions: Both the drugs were able to postpone the delivery for 48 hours. Nifedipine was found to be superior to nitroglycerin dermal patch in prolongation of gestational age at the time of delivery, in perinatal outcome and maternal acceptance.
\end{abstract}

Keywords: Gestational age, Nifedipine, Nitroglycerin, Preterm labor, Tocolysis

\section{INTRODUCTION}

Preterm labor is most vexing problem in obstetric practice. It is more of symptoms than an actual diagnosis. It represents a serious public health problem in $7-12 \%$ of the pregnancies results in up to $70-80 \%$ of neonatal morbidity and mortality. ${ }^{1}$ Inspite of improvement in antenatal care, preterm labor remain in important obstetric problem and poses the greatest risk of the newborn infants.

American academy of Pediatrics and American College of Obstetrics and Gynecology (ACOG) (1997) document preterm labor between 20-37 weeks of gestation if uterine contractions occurring at a frequency of 4 in 20 minutes or 8 in 60 minute plus progressive change in cervix, cervical effacement $80 \%$ of greater and cervical dilation $>1 \mathrm{~cm}$. However preterm labor not restricted to these sign and symptoms according to 2008 definition of ACOG.

If uterine contractions are perceived in the absence of cervical change the condition is called threatened preterm labor. Although it is impossible to predict the chances of giving birth prematurely but the various high-risk factor like previous preterm deliveries, low socioeconomic 
status, maternal age less than 18 years or more than 40 years, premature rupture of membranes, spontaneous second trimester abortions, uterine cause and presence of retained Intrauterine device are associated with preterm labor.

The aim of tocolytic therapy is to prevent uterine contraction, prolong pregnancy and prevent premature birth. The major advantages of tocolysis are the possibility of administering steroid therapy and transfer of mother before delivery to higher center for better neonatal care.

Tocolytics in current use are calcium channel blockers, nitric oxide donors, progesterones, beta adrenergic agonists, prostaglandin synthetase inhibitors, oxytocin receptor antagonist, magnesium salts. $^{2}$ The present pharmacologic measure are aimed specifically for stopping uterine activity at the level of myocyte.

Nitroglycerin; Nitroglycerin skin patch, worldwide also known as glyceryl trinitrate (GTN). It is a low molecular weight nitrate which is highly volatile in nature and also known as nitro vasodilator. Nitroglycerine is a drug with a high first pass inactivation in liver. The active substance is rapidly metabolized in the liver by a glutathione dependent organic nitrate reductase.

To avoid it, transdermal use of the drug is beneficial. 3 This transdermal delivery system contains $25 \mathrm{mg}$ nitroglycerin. It releases $5 \mathrm{mg}$ of nitroglycerin in 24 hours with drug releasing area of $10 \mathrm{~cm}^{2}$. Nitroglycerin is a nitric oxide donor activates Guanyl cyclase and increase synthesis of cyclic 3, 5 Guanosine monophosphate (cGMP) which cause relaxation of smooth muscles. Nitric oxide concentration in increased during pregnancy to maintain quiescent uterus and decreased production occur during labor which explains role of nitroglycerin in arresting preterm labor.

Nifedipine; Nifedipine is pyridine derivative. Nifedipine is most common calcium channel blocker used for tocolysis. Nifedipine blocks the voltage dependant calcium channels in the plasma membrane.

It also inhibits release of intracellular calcium from sarcolemmel stores and increase calcium efflux from the cell. The resultant decrease in intracellular free calcium leads to inhibition of calcium dependant MLCK (Myosin Light Chain Kinase) phosphorylation and results in myometrial relaxation.

Various tocolytic therapy have been tried to prevent preterm births with various success rate. ${ }^{2}$ Efforts have been made to establish a method which is least cumbersome with minimum side effect and allows the patients to remain ambulatory.

This prospective study represents our experience of use of nitroglycerin skin patches and nifedipine in preterm labor and discusses their merits and demerits, as well as success of treatment in comparison to each other.

\section{METHODS}

After taking written informed consent of the patients, this prospective clinical trial was conducted on 100 women, presenting to labor room in a tertiary care teaching hospital with signs and symptoms of preterm labor between gestational ages 26-37 weeks meting all inclusion criteria.

\section{Inclusion criteria}

- Women between 20 to 36 weeks gestational age based on menstrual dates or earliest USG.

- $\quad$ Preterm labor i.e.

a) At least four painful contractions in 20 minutes.

b) Change in cervix, change in Bishop Score $>5$.

c) Effacement (length) of cervix $<3 \mathrm{~cm}$ but $>1 \mathrm{~cm}$.

d) Cervical dilatation of $>1 \mathrm{~cm}$ but not $>4 \mathrm{~cm}$.

- $\quad$ Singleton pregnancy.

- Case with intact membranes.

- Presence of live foetus

\section{Exclusion criteria}

- Any maternal (e.g. significant APH) or foetal (nonreassuring heart rate pattern) $\mathrm{j}$ condition necessitating immediate delivery.

- Severed anemia.

- Multiple gestation (twins, triples etc.)

- Hydramnios.

- Premature rupture of membranes.

- Intrauterine foetal demise or lethal foetal anomalies.

- Cervical dilation $>4 \mathrm{cms}$.

- Treatment with other tocolytics within 24 hours.

These women were divided in two groups -

Group A In 50 women transdermal nitroglycerin skin patch was applied for tocolysis and its maternal and foetal effect and outcome was studied. Group B In 50 women oral nifedipine given for tocolysis and its maternal and foetal effect and outcome was studied. .

Blood pressure, heart rate and feotal heart monitored every 15 minutes in 1 st hour then every $30 \mathrm{~min}$. in 2 nd hour and then every 4 hourly.

Any side effects like nausea, flushing, headache, hypotension, foetal and maternal tachycardia etc. were noted. Treatment was considered successful if contractions stopped and no recurrence of contractions occurred within 48 hours of stopping treatment and pregnancy continued beyond 36 weeks.

Women were followed up to the delivery. Primary outcome of the study was to delay the delivery for at least 
48 hours to buy the time for administration of corticosteroids. Other outcomes were gestational age at the time of delivery, prolongation of labor, effect on neonate, adverse effects on mother and overall success rate.

\section{Statistical analysis}

The observations recorded in all the groups were tabulated and statistical analysis carried out by using statistical software SPSS 20. Data were presented in terms of mean \pm standard deviation (SD) for numerical variables and in percentage for quantitative variables.

Comparison of numerical variables between study groups was done using student t-test and for comparing categorical data chi square( $\mathrm{x})$ test was performed. $\mathrm{P}$ value $<0.05$ was considered as statistically significant whereas $\mathrm{P}$-value $<0.01$ taken to be statistically highly significant.

\section{RESULTS}

Incidence of preterm labor was highest in 21-30 years of age $(64 \%$ and $66 \%)$ in patients treated with nitroglycerin and nifedipine respectively. Most of patients were primigravida or second gravida in both groups. Previous obstetrics history was similar in both groups regarding mean rate of previous preterm delivery/abortions.

The table 1 shows that two study groups are comparable with regards to their clinical characteristics at the beginning of therapy. Both groups were comparable in cervical effacement in $\mathrm{cm}(2.34 \pm 0.48$ vs. $2.33 \pm 0.42)$, cervical dilatation in $\mathrm{cm}(1.93 \pm 0.72$ vs. $1.48 \pm 0.58)$ and gestational age in weeks at the time of enrollment $(32 \pm$ 3.08 vs. $32.28 \pm 2.60)$ (Table 1$)$.

Table 1: Table showing the comparability of study groups.

\begin{tabular}{|c|c|c|c|c|}
\hline \multirow[t]{2}{*}{$\begin{array}{l}\text { Criteria at the } \\
\text { start of treatment }\end{array}$} & \multicolumn{2}{|c|}{$\begin{array}{l}\text { Nitroglycerin } \\
\text { group }\end{array}$} & \multicolumn{2}{|c|}{$\begin{array}{l}\text { Nifedipine } \\
\text { group }\end{array}$} \\
\hline & Mean & SD & Mean & $\mathrm{SD}$ \\
\hline Age (years) & 22.5 & 3.63 & 22.98 & 3.61 \\
\hline Gravida & 2.23 & 1.13 & 2.18 & 1.25 \\
\hline $\begin{array}{l}\text { Duration of } \\
\text { pregnancy (weeks) }\end{array}$ & 32 & 3.08 & 32.28 & 2.60 \\
\hline $\begin{array}{l}\text { Cervical dilatation } \\
(\mathrm{cm})\end{array}$ & 1.93 & 0.72 & 1.48 & 0.58 \\
\hline $\begin{array}{l}\text { Cervical effacement } \\
(\mathrm{cm})\end{array}$ & 2.34 & 0.48 & 2.33 & 0.42 \\
\hline
\end{tabular}

$\mathrm{P}$ value $.001(\mathrm{HS})^{*}$ Data in table 2 depicts $76 \%$ of patients nitroglycerin group were delivered after 36 weeks of gestation and $88 \%$ of patients in nifedipine group were delivered after 36 weeks of gestation.

Mean gestational age at the time of delivery in nitroglycerin group was 34.93 weeks. Mean gestational age at the time of delivery in nifedipine group was 36.42 weeks.

Table 2: Distribution of patients according to gestational age at the time of delivery.

\begin{tabular}{|lllll|}
\hline Gestational score & \multicolumn{2}{l}{ Nitroglycerin } & \multicolumn{2}{l|}{ Nifedeipine } \\
\hline $20-28$ & No. & $\%$ & No. & $\%$ \\
\hline $28-30$ & 1 & 2.0 & 0 & 0 \\
\hline $30-32$ & 0 & 0 & 0 & 12.0 \\
\hline $32-34$ & 1 & 2.0 & 1 & 2.0 \\
\hline $34-36$ & 4 & 8.00 & 1 & 2.0 \\
\hline$>36$ & 6 & 12.0 & 4 & 8.0 \\
\hline Total & 38 & 76.0 & 44 & 88.00 \\
\hline Mean & 50 & 100.0 & 50 & 100.0 \\
\hline SD & 34.93 & & $36.42^{*}$ \\
\hline
\end{tabular}

Table 3 judges the clinical outcomes of baby, assessed by fetal weight and Apgar score at 5 minute which was 2.42 $\mathrm{kg}$ and 8.44 in nitroglycerin group and $2.76 \mathrm{~kg}$ and 8.89 in nifedipine group respectively. Of these babies delivered $86 \%$ had uneventful perinatal period in nitroglycerin group and $96 \%$ in nifedipine group.

Table 3: Comparison of clinical outcome of neonates.

\begin{tabular}{|llllll|}
\hline $\begin{array}{l}\text { At delivery } \\
\text { and } \\
\text { postnatal } \\
\text { period }\end{array}$ & $\begin{array}{l}\text { Nitroglycerin } \\
\text { group }\end{array}$ & $\begin{array}{l}\text { Nifedipine } \\
\text { Group }\end{array}$ & $\begin{array}{l}\text { P } \\
\text { value }\end{array}$ \\
\hline & Mean & SD & Mean & SD & \\
\hline $\begin{array}{l}\text { Foetal weight } \\
\text { APGAR }\end{array}$ & 2.42 & 0.40 & 2.76 & 0.48 & $\begin{array}{l}0.01 \\
(\mathrm{~S})^{*}\end{array}$ \\
$\begin{array}{l}\text { APG } \\
\text { score }\end{array}$ & 8.44 & 0.98 & 8.89 & 1.04 & $\begin{array}{l}0.03 \\
(\mathrm{~S})^{*}\end{array}$ \\
\hline $\begin{array}{l}\text { Uneventful } \\
\text { perinatal } \\
\text { period }\end{array}$ & $86 \%$ & & $96 \%$ & & \\
\hline
\end{tabular}

Gestational age at the time of delivery in weeks $(34.93 \pm 2.13$ versus $36.42 \pm 2.19)$ ( $\mathrm{p}<0.01)$, prolongation of pregnancy in days $(18.46 \pm 14.97$ versus $19.24 \pm 12.50)$ ( $\mathrm{p}>0.05)$, neonatal Apgar score at 5 minute $(8.44 \pm 0.98$ versus $8.89 \pm 1.04)(\mathrm{p}<0.05)$, neonatal weight in $\mathrm{kg}$ $(2.42 \pm 0.40$ versus $2.76 \pm 0.48) \quad(\mathrm{p}<0.05)$ and foetal outcomes was better with nifedipine (group B) in comparison of nitroglycerin (group A) ( Table 2 and 3).

The data in Table 4 depicts in nitroglycerin group the side effect reported was headache in $40 \%$ of patients, nausea in $6 \%$, vomiting in $6 \%$, local irritation in $6 \%$.

In nifedipine group 24\% patients reported headache, $4 \%$ suffered from nausea and only $2 \%$ patients suffered vomiting.

Overall incidence of side effects in nitroglycerin group was $80 \%$ and in nifedipine group was $50 \%$. 
Table 4: Distribution of patients according to side effect.

\begin{tabular}{|lllll|}
\hline Side effect & \multicolumn{2}{l}{ Nitroglycerin } & \multicolumn{2}{l|}{ Nifedipine } \\
\hline Headache & No. & \% & No. & \% \\
\hline Flushing & 3 & 40 & 12 & 24 \\
\hline Nausea & 3 & 6 & 3 & 6 \\
\hline Vomiting & 3 & 6 & 1 & 4 \\
\hline $\begin{array}{l}\text { Maternal } \\
\text { tachycardia }\end{array}$ & 3 & 6 & 3 & 6 \\
\hline Palpitation & 3 & 6 & 3 & 6 \\
\hline Hypotension & 0 & 0 & 0 & 0 \\
\hline Local irritation & 3 & 6 & 0 & 0 \\
\hline Dizziness & 2 & 4 & 1 & 2 \\
\hline Total & 40 & 80 & 25 & 50 \\
\hline
\end{tabular}

Table 5 illustrate the success in the two groups. Majority of the patients. i.e. $76 \%$ in nitroglycerin group and $88 \%$ in nifedipine group where able to prolog pregnancy beyond 36 weeks.

Table 5: Treatment success and failure.

\begin{tabular}{|lllll|}
\hline & \multicolumn{2}{c}{ Nitroglycerin } & \multicolumn{2}{c|}{ Nifedipine } \\
& No & $\%$ & No & $\%$ \\
\hline Success & 38 & 76.00 & 44 & 88.00 \\
\hline Failure & 12 & 24.00 & 6 & 12.0 \\
\hline Total & 50 & 100.00 & 50 & 100.00 \\
\hline
\end{tabular}

\section{DISCUSSION}

Despite advances in perinatal medicine the incidence of preterm birth has increased since the early 1980 . Neonatal morbidity and mortality increase with preterm delivery. For example, the incidence of severe intraventricular hemorrhage decreases after 27 weeks and rare after 32 weeks and incidence of necrotizing and respiratory distress syndrome also decreases with advancing gestational age.

A number of tocolytics have been advocated for the treatment of threatened preterm labor in order to delay delivery. The rationale is that a delay in delivery may be associated with improved neonatal morbidity or mortality. Nitric oxide donors, such as nitroglycerin, have been used to relax the uterus. This review addresses their efficacy, side effects and influence on neonatal outcome. There was reduction in number of deliveries less than 37 weeks with nitric oxide donors when compared with alternative tocolytics. Side effects were reduced in women who received nitric oxide donors rather than other tocolytics. However, women were significantly more likely to experience headache when nitric oxide donors had been used. . $^{4}$

In a meta-analysis Conde-Agudelo $\mathrm{A}$ et al evaluated the efficacy and safety of transdermal nitroglycerin as a tocolytic agent in women with preterm labor.6 Thirteen studies were included. There were no significant differences between transdermal nitroglycerin and placebo for delivery within 48 hours of the initiation of treatment or at $<28$, $<34$, or $<37$ weeks of gestation, adverse neonatal outcomes, and neurodevelopmental status at 24 months of life. When compared with $\beta 2$ adrenergic receptor agonists, transdermal nitroglycerin was associated with a significant reduction in the risk of preterm birth at $<34$ and $<37$ weeks of gestation, admission to the neonatal intensive care unit, use of mechanical ventilation, and maternal side effects. There were no significant differences between transdermal nitroglycerin and nifedipine and magnesium sulfate in delivery within 48 hours of treatment and pregnancy prolongation, respectively. Overall, women who received transdermal nitroglycerin had a higher risk of headache. Present study also supports this where headache was found in $40 \%$ patients.

Controlled-release drug delivery systems studied by Katz $\mathrm{B}$ et al. Oral and transcutaneous controlled-release systems allow relatively short-acting drugs to be administered once or twice daily with comparable therapeutic efficacy and fewer adverse reactions compared with standard formulations. ${ }^{7}$ They can provide decreased fluctuations in drug concentrations in plasma while possibly reducing the total amount of drug necessary for a clinical response. Calcium-channel blocking agents, nitrates, $\beta$-blocking agents, antiarrhythmic agents, clonidine, and nicotinic acid can be administered by these techniques, which have greatly influenced the application of these drugs in clinical practice. So, in present study we choose transdermal nitroglycerine.

Role of transdermal nitroglycerin in patients with severe pre-eclampsia with placental insufficiency studied by Trapani A et al. ${ }^{8}$ They studied it effect on uterine, umbilical and fetal middle cerebral artery resistance indices. Similar study was done by Cacciatore B et al who studied effects of transdermal nitroglycerin on impedance to flow in the uterine, umbilical, and fetal middle cerebral arteries in pregnancies complicated by preeclampsia and intrauterine growth retardation. ${ }^{9}$ They concluded that transdermal administration of nitroglycerin may offer a potential for treatment for patients with preeclampsia who have increased uteroplacental impedance. So, this can be used in patients of preterm labor suffered from preeclampsia.

In a randomized multicenter trial Papatsonis DN et al compared the efficacy of nifedipine with ritodrine in the management of preterm labor.10 Ritodrine was discontinued in 12 patients because of severe maternal side effects and their results were excluded from further analysis. There were significantly fewer maternal side effects in the nifedipine group. Apgar scores and umbilical artery and vein pHs were similar in both groups. The number of admissions to the neonatal intensive care unit (NICU) in the nifedipine group was 
significantly lower than in the ritodrine group (68.4 versus $82.1 \%, \mathrm{P}=0.04)$. Nifedipine in comparison with ritodrine in the management of preterm labor is significantly associated with a longer postponement of delivery, fewer maternal side effects, and fewer admissions to the NICU. These results were in concordance to present study in respect to nifedipine group.

The efficacy of an orally administered calcium antagonist, nifedipine, in suppressing premature uterine activity, was compared with intravenous ritodrine and no treatment by Read MD, Well by DE. ${ }^{11}$ Nifedipine was found to be significantly more effective than ritodrine or withholding therapy and was almost devoid of sideeffects. In present study also, fewer side effects were found with nifedipine in comparison to nitroglycerine.

The effect of the calcium antagonist nifedipine on premature labor was investigated by Ulmsten U et al in ten carefully selected patients. ${ }^{12}$ The main aim of treatment was to inhibit uterine activity and delivery for 3 days during which time fetal lung maturation was accelerated by glucocorticoid treatment. In all 10 patients, uterine activity was abolished during the 3 days of treatment and delivery was also postponed. No serious maternal side effects were observed. All children were delivered in good condition. All survived and were alive and well at 1 year. We were also found same results in nifedipine group.

In a randomized study efficacy and safety of nifedipine versus magnesium sulfate in arresting preterm labor and the efficacy of nifedipine versus terbutaline in preventing recurrent labor was studied by Glock JL et al. ${ }^{13}$ Singleton pregnancies at $<34$ weeks in preterm labor were randomized to either oral nifedipine or intravenous magnesium sulfate. In case of tocolysis failure ritodrine was added. After labor was arrested, the patients in the nifedipine group were maintained on oral nifedipine, and those in the magnesium sulfate group were treated with oral terbutaline until completing 34 weeks. Oral nifedipine is as effective as magnesium sulfate and terbutaline in arresting and preventing idiopathic preterm labor.

A systematic review to know the evidence and protocol for administration of nifedipine and to access its effects on maternal, fetal and neonatal outcomes in preterm labor was done by King JF et al. It was concluded that Calcium channel blockers (especially nifedipine) can be considered safer and more effective tocolytic agents than betamimetics. Similar results were found in present study with nifedipine. ${ }^{14}$

In a prospective, randomized trial nifedipine versus ritodrine for suppression of preterm labor was studied by Kupferminc $M$ et al. ${ }^{15}$ Maternal side effects were significantly less common in the nifedipine group (27\%) than in the ritodrine group $(77 \%)(\mathrm{P}<0.001)$. The neonatal outcome was similar in the two groups. The fall in mean arterial and diastolic blood pressure, and the rise in maternal heart rate were significantly greater in the women who received ritodrine compared with those treated with nifedipine. So, it was concluded that nifedipine is as effective as ritodrine in suppressing preterm labor. Its use was associated with less frequent side effects as we also found this in present study.

Tocolysis for acute preterm labor was studied by Haram $\mathrm{K}$ et al. $^{16}$ In a randomized clinical trial transdermal nitroglycerin was compared with oral nifedipine for suppression of preterm labor by Ghomian $\mathrm{N}$ et al. ${ }^{17}$ They found suppression of uterine contractions 48 hours after starting medication was significantly more common in the GTN group than in the nifedipine group $(44.64 \%(\mathrm{n}=$ $25 / 56)$ vs. $\mathrm{n}=10, \mathrm{P}=0.002)$. Their results were in contrast to present study.

Comparison between nitroglycerin dermal patch and nifedipine for treatment of preterm labor in a randomized clinical trial was done by Kashanian $\mathrm{M}$ et al. ${ }^{18}$ Women of the two groups were followed up to delivery and were compared according to arrest of labor for 2 hours, 48 hours, 7 days, gestational age at the time of delivery and their adverse effects. Apgar score of minutes 5, $(\mathrm{P}=0.03)$ and neonatal weight $(\mathrm{P}=0.04)$, were more and cesarean deliveries, neonatal intensive care unit (NICU) admission and duration of NICU stay were less in the NG group. Adverse effects were similar, minimal and negligible in both groups. In contrast to our results they concluded that the NG patch is a more effective method for preterm labor control than nifedipine with regard to minimal side effects.

In another randomized controlled trial Dhawle A et al compared the safety and efficacy of oral nifedipine with transdermal nitroglycerin (NTG) in the inhibition of preterm labour. ${ }^{19}$ The neonatal outcomes in terms of the mean birth weight, incidence of low birth weight and very low birth weight babies, need and duration of neonatal intensive care was similar in both groups. Their results were similar to ours that oral nifedipine is a safe and effective tocolytic with a lower failure rate and better side effect profile as compared with transdermal nitroglycerin. Their results were in concordance to present study that Nitroglycerine patch was as effective as Nifedipine in suppression of preterm labour. ${ }^{20}$

\section{CONCLUSION}

Both nitroglycerin and nifedipine can delay the preterm labor beyond 48 hours. However, nifedipine is found to be superior to nitroglycerin skin patch in prolongation of gestational age at the time of delivery, better maternal acceptance and better perinatal outcome.

Funding: No funding sources

Conflict of interest: None declared 
Ethical approval: The study was approved by the Institutional Ethics Committee

\section{REFERENCES}

1. Creasy RK: Preterm birth prevention. Where are we?. AM J Obstet Gynecol. 1993;168(4):1223-30.

2. Haram K, Mortensen JH, Morrison JC. Tocolysis for acute preterm labor: does anything work. J Matern Fetal Neonatal Med. 2015;28(4):371-8.

3. Robertson RM and Robertson D: Drugs used for the treatment of myocardial ischemia. In: Joel GH, Alfred Goodman Gilman, Lees EL (eds), Goodman and Gilman's the pharmacological basis of therapeutics. 9th edition, McGraw Hill. 1996; pp759779.

4. Jeyabalan A, Caritis SN. Pharmacologic inhibition of preterm labor. Clin obstet Gynecol. 2002;45(1):99113.

5. Duckitt K, Thornton S. Nitric oxide donors for the treatment of preterm labour. Cochrane Database Syst Rev. 2002;3(3):CD002860.

6. Conde-Agudelo A, Romero R. Transdermal nitroglycerin for the treatment of preterm labor: a systematic review and metaanalysis. Am J of Obstet Gynecol. 2013;209(6):551-e1.

7. Katz B, Rosenberg A, Frishman WH. Controlledrelease drug delivery systems in cardiovascular medicine. Am Heart J. 1995;129(2):359-68.

8. Trapani A, Gonçalves LF, Pires MD. Transdermal nitroglycerin in patients with severe pre-eclampsia with placental insufficiency: effect on uterine, umbilical and fetal middle cerebral artery resistance indices. Ultrasound Obstet Gynecol. 2011;38(4):38994.

9. Cacciatore B, Halmesmäki E, Kaaja R, Teramo K, Ylikorkala O. Effects of transdermal nitroglycerin on impedance to flow in the uterine, umbilical, and fetal middle cerebral arteries in pregnancies complicated by preeclampsia and intrauterine growth retardation. 1998;179(1):140-5.

10. Papatsonis DN, Van Geijn HP, Ader HJ, Lange FM, Bleker OP, Dekker GA. Nifedipine and ritodrine in the management of preterm labor: a randomized multicenter trial. Obstet Gynecol. 1997;90(2):230-4.
11. Read MD, Wellby DE. The use of a calcium antagonist (nifedipine) to suppress preterm labour. BJOG 1986 ;93(9):933-7.

12. Ulmsten U, Andersson KE, Wingerup L. Treatment of premature labor with the calcium antagonist nifedipine. Arch Gynecol.1980;229(1):1-5.

13. Glock JL, Morales WJ. Efficacy and safety of nifedipine versus magnesium sulfate in the management of preterm labor: a randomized study. Am J of Obstet Gynecol. 1993;169(9):960-4.

14. King JF, Flenady V, Papatsonis D, Dekker G, Carbonne B. Calcium channel blockers for inhibiting preterm labour; a systematic review of the evidence and a protocol for administration of nifedipine. Aust NZ J of Obstet Gynaecol. 2003;43(3):192-8.

15. Kupferminc M, Lessing JB, Yaron Y, Peyser MR. Nifedipine versus ritodrine for suppression of preterm labour. BJOG 1993;100(12):1090-4.

16. Haram K, Mortensen JH, Morrison JC. Tocolysis for acute preterm labor: does anything work. J Matern Fetal Neonatal Med. 2015 ;28(4):371-8

17. Ghomian N, Vahedalain SH, Tavassoli F, Pourhoseini SA, Heydari ST. et al. Transdermal Nitroglycerin Versus Oral Nifedipine for Suppression of Preterm Labor, Shiraz E-Med J. 2015 ;16(11-12):e59923.

18. Kashanian M, Zamen Z, Sheikhansari N. Comparison between nitroglycerin dermal patch and nifedipine for treatment of preterm labor: a randomized clinical trial. J Perinatol. 2014; 34(9):683-7.

19. Dhawle A, Kalra J, Bagga R, Aggarwal N. Nifedipine versus nitroglycerin for acute tocolysis in preterm labour: a randomised controlled trial. Int J of Reprod Contracept Obstet Gynecol. 2016;2(1):61-6.

20. Zulfiqar S, Zulfiqar S, Khan SM. Comparsion of nitroglycerine patch and nifedipine in treatment of preterm labour. JSZMC. 2016;7(2):965-7.

Cite this article as: Kaur M, Goel B, Singh J.

Comparative study of nitroglycerin dermal patch versus nifedipine in the management of preterm labour. Int J Reprod Contracept Obstet Gynecol 2018;7:4243-8. 